\title{
Roles of Solute C and Grain Boundary in Strain Aging Behaviour of Fine-grained Ultra-low Carbon Steel Sheets
}

\author{
Yoshihiko ONO, ${ }^{1) *}$ Yoshimasa FUNAKAWA, ${ }^{2)}$ Kaneharu OKUDA, ${ }^{3)}$ Kazuhiro SETO, ${ }^{2)}$ Naoki EBISAWA, ${ }^{4)}$ \\ Koji INOUE ${ }^{4)}$ and Yasuyoshi NAGAI ${ }^{4}$
}

1) Steel Research Lab., JFE Steel Corp., 1, Kokancho, Fukuyama, Hiroshima, 721-8510 Japan.

2) Steel Research Lab., JFE Steel Corp., 1, Kawasakicho, Chuo-ku, Chiba, 260-0835 Japan.

3) Steel Research Lab., JFE Steel Corp., concurrent with Graduate School of Engineering, Tohoku University, 6-6 Aoba, Aramaki, Aoba-ku, Sendai, Miyagi, 980-8579 Japan.

4) The

Oarai Center, Institute for Materials Research, Tohoku University, 2145-2 Narita, Oarai, Higashiibaraki, Ibaraki, $311-1313$ Japan.

(Received on January 1, 2017; accepted on March 14, 2017; J-STAGE Advance published date: June 20, 2017)

\begin{abstract}
The roles of solute $\mathrm{C}$ and the grain boundary in the strain aging phenomenon of polycrystalline ferritic steel were investigated using Nb-bearing ULC steel sheets with a relatively low solute C content of 1-3 ppm and ferrite grain sizes of $9.5 \mu \mathrm{m}$ and $183 \mu \mathrm{m}$ at aging temperatures from 70 to $400^{\circ} \mathrm{C}$. The steels exhibited two definite hardening stages. The 1st hardening stage appeared in both fine- and coarsegrained specimens, in which the increase in YP ( $\triangle Y P$ ) became saturated at around $30 \mathrm{MPa}$. From the apparent activation energy and hardening kinetics, the hardening mechanism was assumed to be dislocation pinning by solute $\mathrm{C}$ atoms. The 2 nd hardening stage, significantly appeared in fine-grained specimens accompanying a large increase in the Hall-Petch coefficient; $\triangle \mathrm{YP}$ was quite large, reaching $90 \mathrm{MPa}$. Fine precipitates were not detected in aged specimens observed by TEM and 3DAP. Segregation of solute C to the grain boundaries and diffusion of $\mathrm{Fe}$ atoms in the grain boundaries were proposed as possible mechanisms of this 2 nd hardening. Grain-boundary hardening was assumed to be one of the hardening mechanisms in the strain aging in polycrystalline ferritic steel.
\end{abstract}

KEY WORDS: strain aging; grain boundary; segregation; solute C; 3DAP; precipitation; activation energy; Nb-bearing steel; Hall-Petch coefficient; $k_{y}$.

\section{Introduction}

Several mechanisms have been proposed for the stainaging phenomenon of steels that contain solute $\mathrm{C}$ and $\mathrm{N}$. The major mechanisms currently accepted are dislocation pinning by solute $\mathrm{C}$ or $\mathrm{N}$ atoms ${ }^{1-4)}$ and precipitation hardening. ${ }^{5-8)}$ Steels with a trace amount of solute $\mathrm{C}$ tend to exhibit a single hardening stage; the mechanism is assumed to be dislocation pinning by solute $\mathrm{C}$ atoms. ${ }^{4}$ Low carbon and ultra-low carbon steels with large amount of solute $\mathrm{C}$ often exhibit a second hardening stage after the first one; the mechanism is assumed to be precipitation of carbides. ${ }^{4-7,9)}$

This phenomenon is also known to be influenced by the ferrite grain size, ${ }^{3,9-13)}$ the site of solute atoms, ${ }^{11)}$ the dislocation density and the deformation path. ${ }^{14-16)}$ For example, hardening behaviour is enhanced by grain refinement ${ }^{3,9-13)}$ and the Hall-Petch coefficient, $k_{y}$, increases during aging. ${ }^{3,9,10,13)}$ The effect of grain refinement hardly appears at room temperature but dominantly appears at elevated temperatures around $170^{\circ} \mathrm{C} .{ }^{11)}$ This means that the grain boundary affects strain aging under a specific aging condition. Two possible mechanisms which explain the

* Corresponding author: E-mail: yos-ono@jfe-steel.co.jp DOI: http://dx.doi.org/10.2355/isijinternational.ISIJINT-2016-622 effect of grain size and the change in $k_{y}$ have been proposed to date. One is a change in the dislocation density ${ }^{12)}$ and the other is segregation of solute elements to the grain boundary during aging. ${ }^{10,13)}$

Recently, effects of the segregated interstitials in the grain boundary on YP were focused on. ${ }^{17-19)}$ The amount of solute $\mathrm{C}$ in the grain boundary greatly affects $k_{y}$ and is assumed to be one of the essential factors defining YP of polycrystalline ferritic steels. ${ }^{17-19)}$ Strain aging at $170^{\circ} \mathrm{C}$ is also well known to be chiefly affected by the solute $\mathrm{C}$ embedded in the grain boundary. ${ }^{11)}$ These results indicate that the segregated solute $\mathrm{C}$ and the grain boundary themselves play essential roles in the strain-aging phenomenon.

In this study, the strain-aging mechanisms of polycrystalline ferritic steel were reconsidered focusing on the roles of solute $\mathrm{C}$ and the grain boundary, using $\mathrm{Nb}$-bearing ultra-low carbon steel sheets which had largely different ferrite grain sizes and contained small amounts of solute C.

\section{Experimental Procedure}

The chemical composition of the steel used was $0.0019 \% \mathrm{C}-0.37 \% \mathrm{Mn}-0.015 \% \mathrm{Nb}$ (mass $\%)$. This material is a commercially-produced $340 \mathrm{MPa}$ grade bake-hardenable steel sheet with the ferrite grain diameter of $9.5 \mu \mathrm{m}$ and 
thickness of $0.75 \mathrm{~mm}$, and is a ferritic single-phase steel containing a small amount of solute $\mathrm{C}$. $\mathrm{N}$ is fully stabilized as $\mathrm{AlN}$ or $\mathrm{Nb}(\mathrm{C}, \mathrm{N})$ during hot rolling and annealing process. Figure 1 shows a schematic diagram of the experimental procedure. The as-received steel sheets were skin-pass rolled with the elongation of $3.6 \%$ and annealed at $850^{\circ} \mathrm{C}$ for $10 \mathrm{~min}$ to obtain a large-grained microstructure by utilizing strain-induced grain growth. The cooling rate was set to $-15^{\circ} \mathrm{C} / \mathrm{sec}$ to retain some amount of solute $\mathrm{C}$. The steel sheets were then skin-pass rolled again with the elongation of $1.4 \%$ and subjected to the following experiments. Asreceived steel sheets were also annealed at $830^{\circ} \mathrm{C}$ for 30 sec to evaluate the mechanical properties in the as-annealed condition.

The strain aging behaviours of former two steels were evaluated using JIS No. 5 specimens perpendicular to rolling direction. The specimens were pre-strained with elongations from 0 to $10 \%$ in tensile strain, and aged at from 70 to $400^{\circ} \mathrm{C}$. They were subjected to the tensile test, microstructural observations by SEM-EBSD (electron backscatter diffraction) and TEM and atomic distribution analysis by 3-dimensional atom probe (3DAP) tomography. Increase in YP during aging, $\triangle \mathrm{YP}$, was evaluated as the increase in upper YP against the pre-strained stress. Bake hardening, $\mathrm{BH}$, was evaluated as the increase in upper YP after aging at $170^{\circ} \mathrm{C}$ for $20 \mathrm{~min}$ against $2 \%$ pre-strained stress. Aging index, A.I., was evaluated as the increase in lower YP after aging at $100^{\circ} \mathrm{C}$ for $1 \mathrm{hr}$ against $8 \%$ pre-strained stress. The tests were carried out with a crosshead speed of $10 \mathrm{~mm} / \mathrm{min}$.

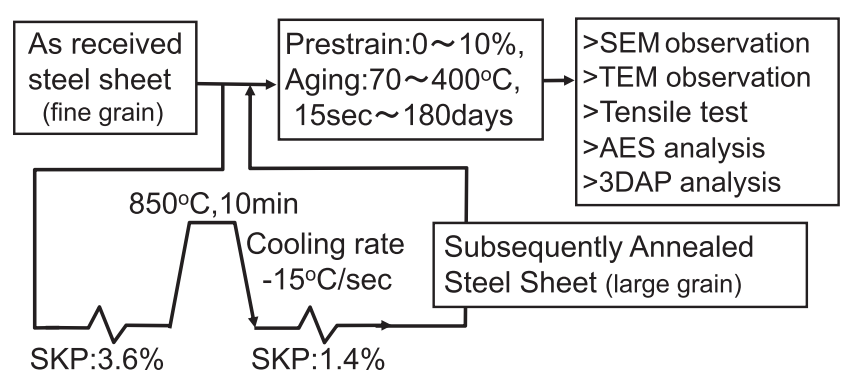

Fig. 1. Schematic illustration showing experimental procedure.
TEM analysis was carried out by the thin-foil technique using a Philips CM200 with the accelerating voltage of $200 \mathrm{kV}$. 3DAP analysis was carried out using an Ametek LEAP 4000XHR in a voltage mode, i.e., without using a laser, to minimize the diffusion of solute elements. In order to investigate the segregation behaviour of solute $\mathrm{C}$ to the grain boundary, AES analysis was carried out using a Philips SAM650. The specimens were skin-pass rolled by $1.8 \%$, aged at $170^{\circ} \mathrm{C}$ for $30 \mathrm{sec}$ to 20 days and deep-drawn to a cylindrical cup with the diameter of $33 \mathrm{~mm}$. Test specimens were then cut from the flange of the cylindrical cup specimens. The test specimens were fractured in a cooled chamber and more than 30 points of the fractured surfaces were analysed expeditiously under a vacuum of less than $10^{-10}$ torr. The dislocation density of the pre-strained specimen was evaluated by the X-ray diffraction method using a Rigaku RU300 and Co radiation source by measuring the half-value widths of the profiles of the (110), (211), (220) reflections. ${ }^{20,21)}$

\section{Experimental Results}

\subsection{Strain Aging Behaviour of Steel Sheets with Differ- ent Ferrite Grain Sizes}

Figure 2 shows the cross-sectional EBSD-IPF maps of the as-received and the subsequently annealed specimens. The average ferrite grain diameters are $9.5 \mu \mathrm{m}$ and $183 \mu \mathrm{m}$, respectively, and from 80 to $85 \%$ of the grain boundaries are high-angle boundaries with a misorientation of more than $15^{\circ}$. Table 1 shows the mechanical properties of each specimen. A.I. of the as-received (fine-grained) and subsequently annealed (large-grained) specimens are $12 \mathrm{MPa}$ and $29 \mathrm{MPa}$, respectively. The amounts of solute $\mathrm{C}$ within the

Table 1. Mechanical properties of steel sheets before aging.

\begin{tabular}{ccccccc}
\hline & $\begin{array}{c}\text { YP } \\
(\mathrm{MPa})\end{array}$ & $\begin{array}{c}\mathrm{TS} \\
(\mathrm{MPa})\end{array}$ & $\begin{array}{c}\text { El } \\
(\%)\end{array}$ & $\begin{array}{c}2 \% \mathrm{WH} \\
(\mathrm{MPa})\end{array}$ & $\begin{array}{c}\text { BH } \\
(\mathrm{MPa})\end{array}$ & $\begin{array}{c}\text { A.I. } \\
(\mathrm{MPa})\end{array}$ \\
\hline As-received & 234 & 359 & 41 & 37 & 34 & 12 \\
Subsequently annealed & 168 & 281 & - & 27 & 31 & 29 \\
\hline
\end{tabular}

(a) $\bar{d}: 9.5 \mu \mathrm{m}$

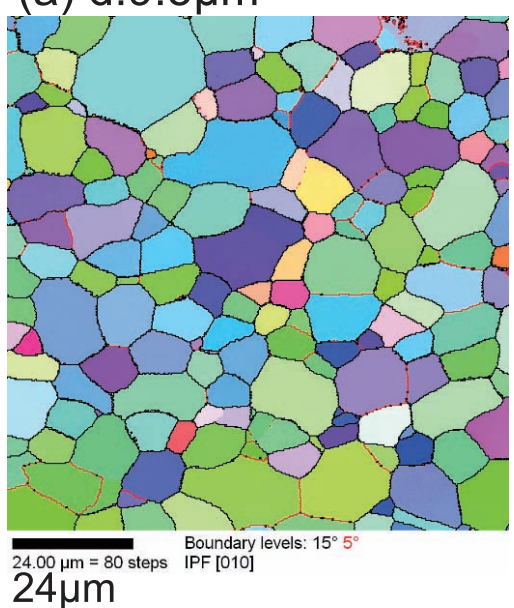

(b) $\overline{\mathrm{d}}: 183 \mu \mathrm{m}$

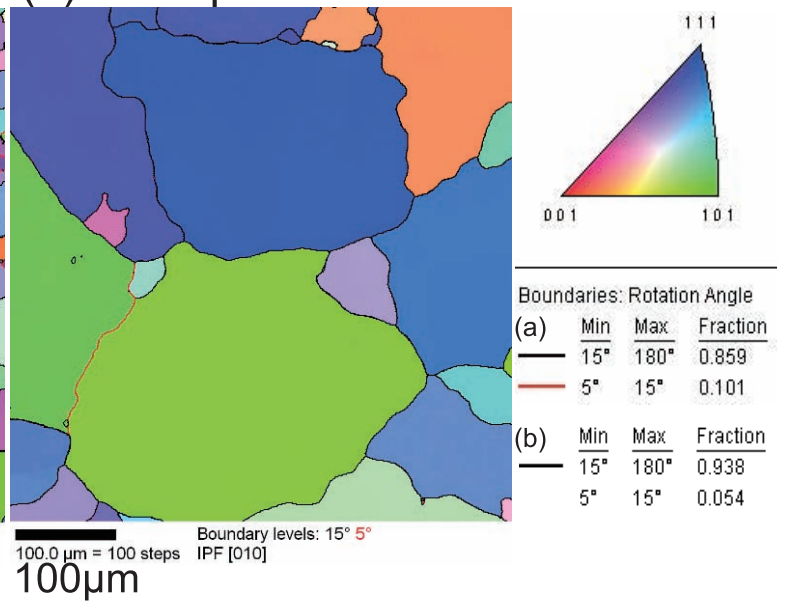

Fig. 2. Cross-sectional EBSD-IPF maps of (a) as-received and (b) subsequently annealed steels. The orientations of the normal direction to the cold-rolled surface are shown. 
grains are estimated to be around 1 and 3 ppm, respectively, from a previous study. ${ }^{22)}$ Although A.I. of the as-received specimen is smaller, its $\mathrm{BH}$ is larger than that of the subsequently annealed specimen. This means that grain refinement contributes to age-hardening at a high temperature of around $170^{\circ} \mathrm{C}$, as previously reported. ${ }^{11)}$

Figure 3 shows the strain-stress curves of the fine-grained specimens aged at $170^{\circ} \mathrm{C}$ after applying $2 \%$ pre-strain. YP increases only after 15 seconds of aging and increases drastically after 20 minutes of aging accompanying the clear yield point. Figure 4 shows the change in $\Delta \mathrm{YP}$ during aging for specimens with different ferrite grain sizes. Two distinct hardening stages (stage I, II) and a subsequent softening stage (stage III) can be seen in the fine-grained specimen, whereas only a single hardening stage occurs in the largegrained specimen. The $\Delta \mathrm{YP}$ of the 1 st hardening becomes saturated at around $30 \mathrm{MPa}$ for both steels, while that of $2 \mathrm{nd}$ hardening reaches around $90 \mathrm{MPa}$. This large 2nd hardening is exhibited at over $100^{\circ} \mathrm{C}$ and continues up to $400^{\circ} \mathrm{C}$. Lower YP also increases as upper YP increases. The change in TS during aging was less than $\pm 3 \mathrm{MPa}$.

The grain-size dependency of YS and the change in the Hall-Petch coefficient, $k_{y}$, during aging are shown in Figs. 5 and 6 respectively. As previously reported, ${ }^{9,23)} k_{y}$ of the asannealed state is quite large, but it drops sharply after skinpass rolling or pre-straining. The $k_{y}$ increases little during the 1 st hardening stage, while increases drastically during

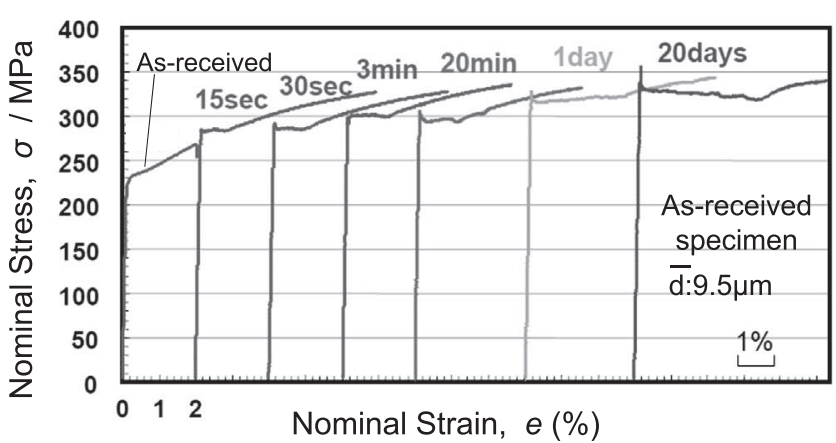

Fig. 3. Strain-stress curves of specimen with a ferrite grain diameter of $9.5 \mu \mathrm{m}$ with $2 \%$ pre-strain. Showing the effect of aging at $170^{\circ} \mathrm{C}$.

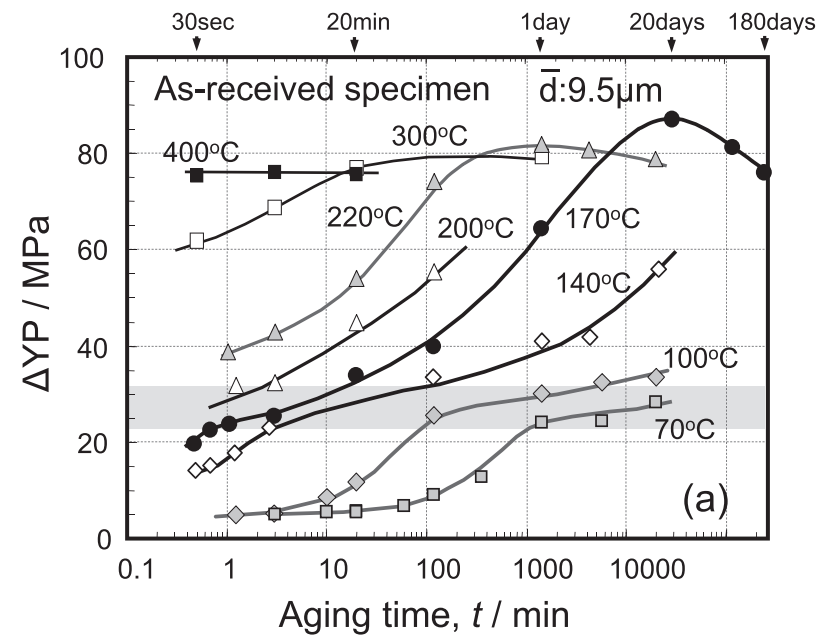

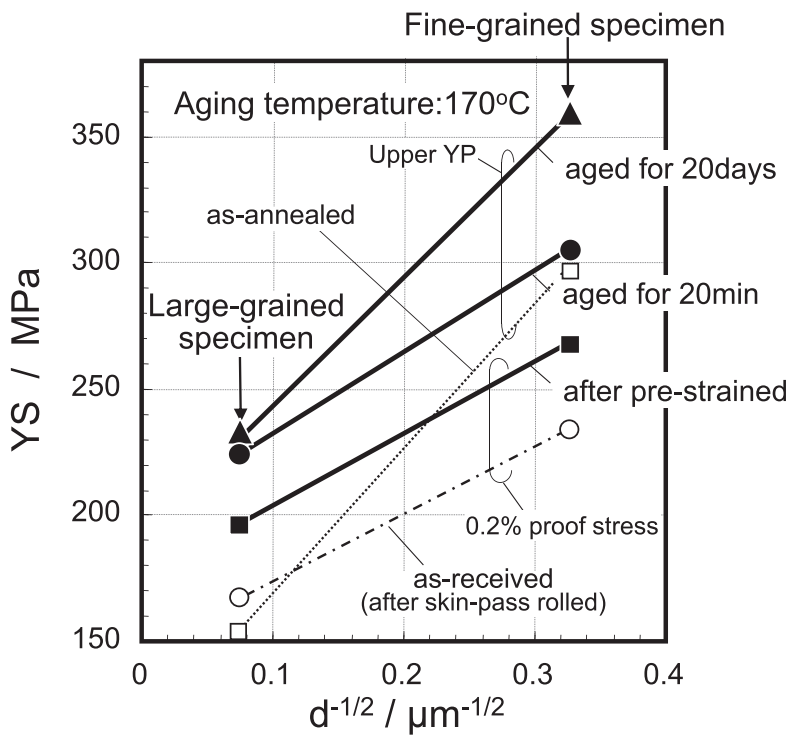

Fig. 5. Grain-size dependency of YS under each condition.

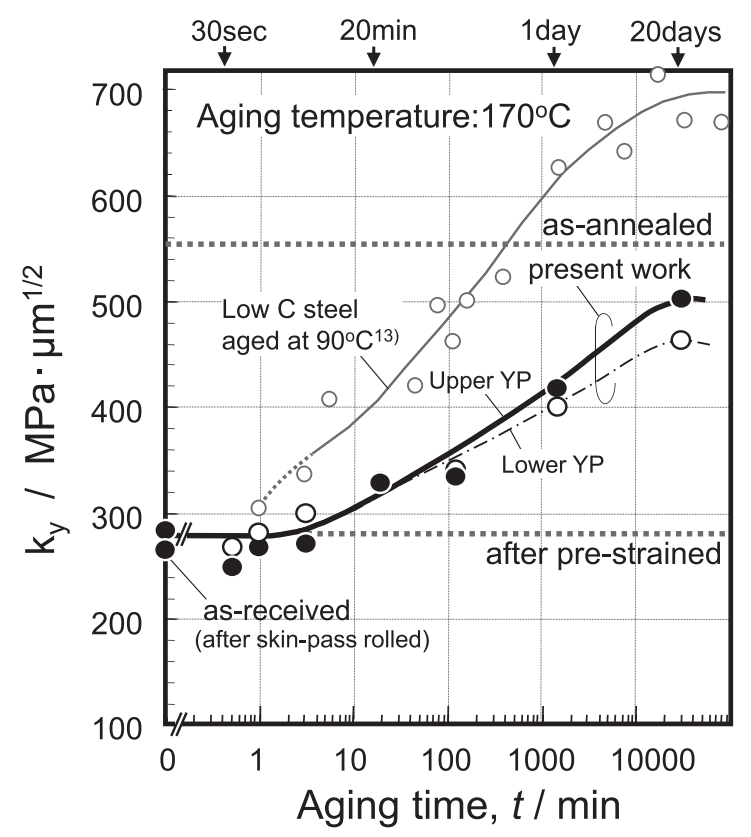

Fig. 6. Change in $k y$ during aging.

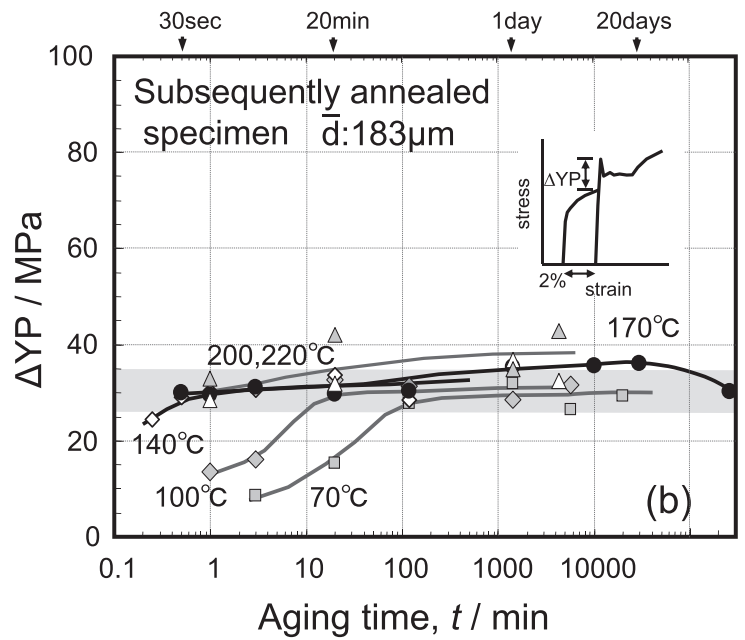

Fig. 4. Aging behaviour of $2 \%$ pre-strained specimens with ferrite grain diameters of (a) $9.5 \mu \mathrm{m}$ and (b) $183 \mu \mathrm{m}$. $\Delta \mathrm{YP}$ is the increment of yield stress by aging treatment. 
the 2nd hardening stage, then becomes saturated at around $500 \mathrm{MPa} \mu \mathrm{m}^{1 / 2}$, which is close to that of the annealed state.

The previously-reported $k_{y}$ of the as-annealed, after straining and after aging conditions are listed in Table 2. Armstrong ${ }^{23)}$ reported that $k_{y}$ of as-annealed $0.1 \% \mathrm{C}$ steel is $742 \mathrm{MPa} \mathrm{m}^{1 / 2}$ and drops to $323 \mathrm{MPa} \mu \mathrm{m}^{1 / 2}$ after applying $2.5 \%$ plastic strain. Wilson ${ }^{13)}$ reported that $k_{y}$ of quenched ultra-low carbon steel increases during aging from 294 $\mathrm{MPa} \mu \mathrm{m}^{1 / 2}$ to around $700 \mathrm{MPa} \mu \mathrm{m}^{1 / 2}$, which is close to the value of slowly cooled steel. Hanai ${ }^{3)}$ also reported that $k_{y}$ increases during aging at $170^{\circ} \mathrm{C}$ for $20 \mathrm{~min}$, and the increment reaches $87 \mathrm{MPa} \mu \mathrm{m}^{1 / 2}$ in batch-annealed steel with 5 ppm of solute $\mathrm{C}$ and $\mathrm{N}$. Although $k_{y}$ of the pre-strained state and the increment of $k_{y}$ during aging at $170^{\circ} \mathrm{C}$ for $20 \mathrm{~min}$ in this work are 283 and $48 \mathrm{MPa} \mathrm{m}^{1 / 2}$, respectively, which are slightly smaller than the previously-reported values, they seem to be consistent because they decrease as the amount

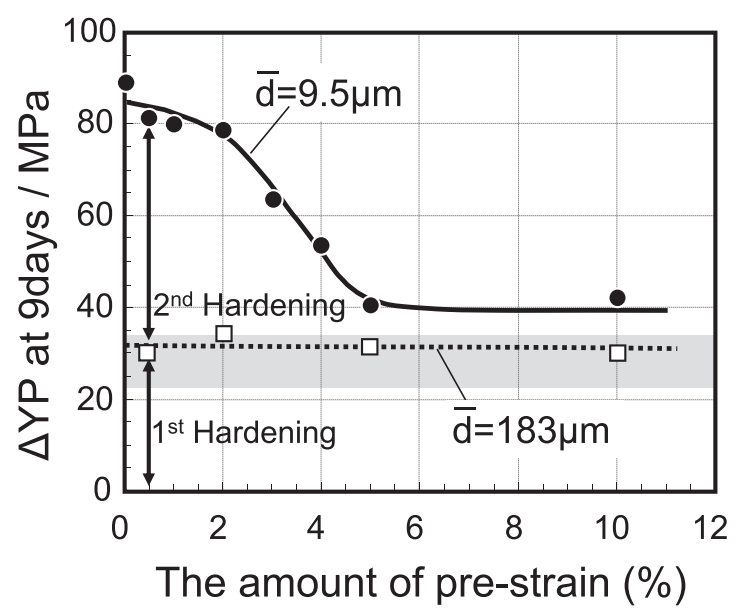

Fig. 7. Relationship between amount of pre-strain and increment of YP after aging at $170^{\circ} \mathrm{C}$ for 9 days. of solute $\mathrm{C}$ decreases, as reported by Takeda ${ }^{18)}$ and Hanai. ${ }^{3)}$

Figure 7 shows the effect of pre-strain on $\Delta Y P$ after aging at $170^{\circ} \mathrm{C}$ for 9 days, which is near the peak aging condition. The 1st hardening is hardly influenced by the amount of pre-strain. This is because the dislocation density is $1.0 \times 10^{14} \mathrm{~m}^{-2}$ and the amount of solute $\mathrm{C}$ is sufficient for the pinning sites of dislocations. ${ }^{4)}$ The 2 nd hardening, however, decreases as the amount of pre-strain increases. It suggests that the amount of the dislocation density is a negative factor for the 2 nd hardening.

\section{Discussion}

As mentioned, the fine-grained steel sheet exhibits distinct 1 st and 2 nd hardening stages, and the 2nd hardening reaches around $90 \mathrm{MPa}$ accompanying a great increase in $k_{y}$, even though the amount of solute $\mathrm{C}$ is quite small. Precipitation hardening ${ }^{5)}$ and grain-boundary segregation of interstitial elements ${ }^{13}$ were believed as mechanisms of the 2nd hardening. In this study, essential roles of solute $\mathrm{C}$ and grain boundaries to the 1st and 2nd hardenings are discussed in terms of microstructural change, hardening kinetics and segregation behaviours.

\subsection{Contribution of Grain Interior and Grain Bound- ary to Age-hardening}

First, the contributions of the grain interior and the grain boundary to the 1 st and 2 nd hardenings are evaluated in the $2 \%$ pre-strained specimens. Yield strength, $\sigma_{y}$, is expressed using strength of the grain interior, $\sigma_{o}$, the Hall-Petch coefficient, $k_{y}$, and the grain size, $d$, as Eq. (1):

$$
\sigma_{y}=\sigma_{0}+k_{y} d^{-1 / 2}
$$

Strength of the grain interior, $\sigma_{0}$ can be estimated as an extrapolated YS when $d^{-1 / 2}$ equals zero. The critical grain-

Table 2. Previously reported $k_{y}$ in as-annealed, after plastic deformation and after aging conditions.

\begin{tabular}{|c|c|c|c|c|}
\hline Materials & Conditions & $k_{y}\left(\mathrm{MPa} \cdot \mu \mathrm{m}^{1 / 2}\right)$ & Tested Temp. & Ref. \\
\hline Al-killed Nb-bearing ULC steel & as-annealed, L.YP/U.YP & $503 / 567$ & R.T. & - \\
\hline ; sol.C $=1-3 \mathrm{ppm}$ & after $2 \%$ pre-straining & 283 & & \\
\hline \multirow[t]{3}{*}{ (present work) } & after aging, $170^{\circ} \mathrm{C}, 1 \mathrm{~min}, \mathrm{~L} . \mathrm{YP} / \mathrm{U} . \mathrm{YP}$ (end of the I stage) & $279 / 283$ & & \\
\hline & after aging, $170^{\circ} \mathrm{C}, 20 \mathrm{~min}, \mathrm{~L} . \mathrm{YP} / \mathrm{U} . \mathrm{YP}$ & $331 / 331$ & & \\
\hline & after aging, $170^{\circ} \mathrm{C}, 20$ days, L.YP/U.YP (end of the II stage) & $463 / 503$ & & \\
\hline \multirow[t]{2}{*}{$0.1 \% \mathrm{C}$ semi-killed steel } & as-annealed, L.YP & 742 & R.T. & 23) \\
\hline & as-annealed, $2.5 \%$ flow stress & 323 & & \\
\hline \multirow[t]{3}{*}{ ULC steel $;$ sol.C $=30 \mathrm{ppm}$} & as-annealed(slowly cooled) & $688-710$ & R.T. & 13) \\
\hline & as-annealed(quenched) & 294 & & \\
\hline & after aging, $90^{\circ} \mathrm{C}, 10^{5} \mathrm{~min}$ & $672-710$ & & \\
\hline $0.015-0.041 \%$ Al-killed steel & (Batch-annealed) & & & \\
\hline \multirow[t]{2}{*}{; sol. $\mathrm{C}+\mathrm{N}=5 \mathrm{ppm}$} & after $2 \%$ pre-straining & 127 & - & 3) \\
\hline & after aging, $170^{\circ} \mathrm{C}, 20 \mathrm{~min}, \mathrm{~L} . \mathrm{YP}$ & 214 & & \\
\hline \multirow[t]{2}{*}{; sol. $\mathrm{C}+\mathrm{N}=10 \mathrm{ppm}$} & after $2 \%$ pre-straining & 115 & - & 3) \\
\hline & after aging, $170^{\circ} \mathrm{C}, 20 \mathrm{~min}, \mathrm{~L} . \mathrm{YP}$ & 285 & & \\
\hline \multirow[t]{2}{*}{; sol. $\mathrm{C}+\mathrm{N}=20 \mathrm{ppm}$} & after $2 \%$ pre-straining & 93 & - & 3) \\
\hline & after aging, $170^{\circ} \mathrm{C}, 20 \mathrm{~min}, \mathrm{~L} . \mathrm{YP}$ & 319 & & \\
\hline
\end{tabular}


boundary strength, $\tau_{c}$, when the dislocation sources operate at or near grain boundaries, i.e., shear stress acting on the grain boundary when yielding occurs, can be theoretically given from $k_{y}$, assuming the pile-up model. ${ }^{24,25)}$ The $k_{y}$ and $\tau_{c}$ are related in the double pile-up model as Eq. (2):

$$
k_{\mathrm{y}}=M \sqrt{\frac{2 G b \tau_{c}}{\pi k}}
$$

where $M$ is the Taylor factor, $G$ is the shear modulus, $b$ is the Burgers vector and $k$ is a constant equal to $(1-v)$ for edge dislocation and 1 for screw dislocation, where $v$ is the Poisson's ratio. $\tau_{c}$ can be estimated by giving the proper values of $M, G, b$ and $k$ in bcc Fe.

Figure 8 shows the estimated $\sigma_{0}$ and $\tau_{c}$ under aging conditions of $70^{\circ} \mathrm{C}$ and $170^{\circ} \mathrm{C}$ when $M, G, b$ and $k$ are given as $2,80 \mathrm{GPa}, 0.25 \mathrm{~nm}$ and 0.85 , respectively. The $\sigma_{0}$ increases during the 1st hardening stage and its increment becomes saturated at around $30 \mathrm{MPa}$, which is independent of aging temperature. On the other hand, $\tau_{c}$ hardly changes during the 1st hardening stage, but increases drastically after the completion of 1 st hardening and reaches $4 \mathrm{GPa}$, which is close to the value of the as-annealed state.

Thus, the 1st hardening seems to be derived from an increase in the strength of the grain interior, and the 2nd hardening, in the strength of around the grain boundary. One of the authors et al. showed that the pop-in load at the grain boundary in the nano-indentation method increased gradually during the 2 nd hardening stage ${ }^{26)}$ which is consistent with the above theory.

Here, there could be two possible processes of increas-

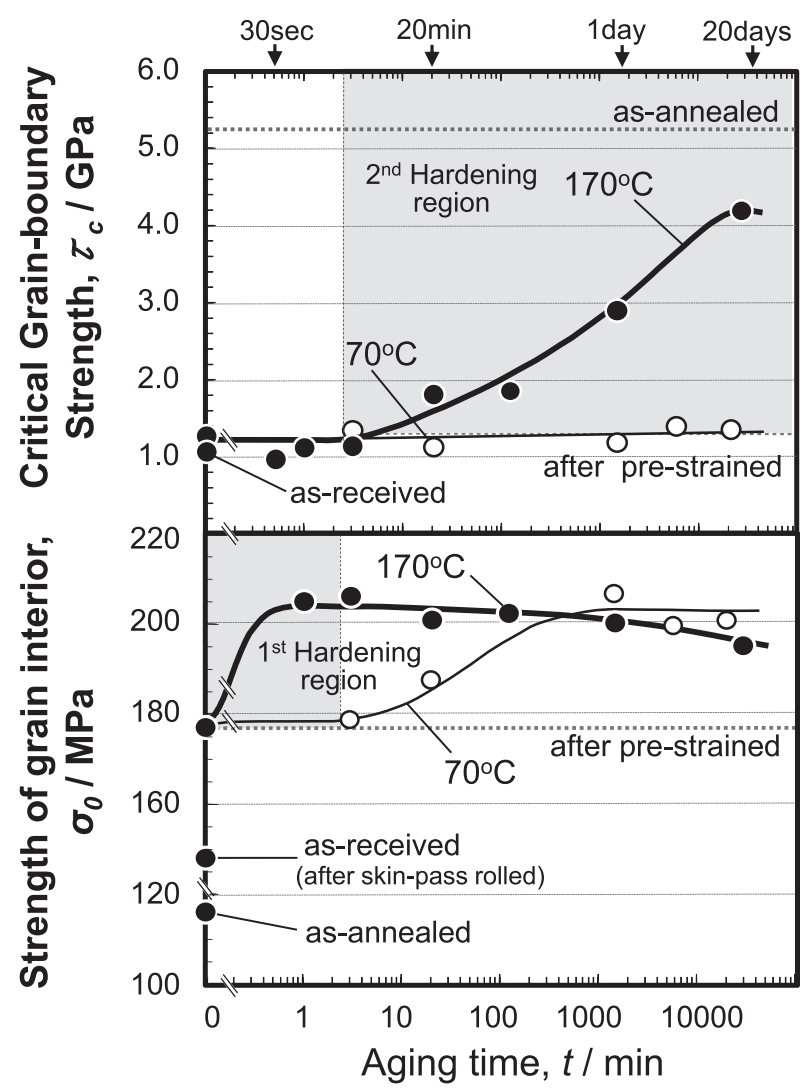

Fig. 8. Changes in critical grain-boundary strength and strength of grain interior during aging. Gray areas show the 1st and $2 \mathrm{nd}$ hardening stages under the aging condition of $170^{\circ} \mathrm{C}$. ing $\tau_{c}$ and $k_{y}$. One is the previously-predicted additional hardening process due to precipitation hardening ${ }^{5)}$ or grainboundary segregation. ${ }^{13)}$ The other is the recovery process of the grain boundary. As shown above, $\tau_{c}$ and $k_{y}$ drop after deformation and increase drastically during aging. Previously, essential reasons for the drop in $k_{y}$ when plastic strain is applied was believed to be the distribution of mobile dislocations, ${ }^{16,23)}$ micro-residual stress ${ }^{14)}$ and inhomogeneous plastic strain. ${ }^{27)}$ The values of $\tau_{c}$ and $k_{y}$ are, however, still quite small even at the end of the 1 st hardening stage. This indicates that the drops in $\tau_{c}$ and $k_{y}$ are chiefly caused by the decrease in the strength of the grain boundary rather than the distribution of mobile dislocations. Then, $\tau_{c}$ and $k_{y}$ increase to near the values of the annealed state during the 2 nd hardening stage. This implies that $\tau_{c}$ and $k_{y}$ simply return from the deformed state to the annealed state during aging by the local recovery around the grain boundary.

\subsection{Kinetics of Age-hardening}

Cottrell and Bilby ${ }^{1)}$ established a kinetic model for dislocation pinning, in which the number of solute atoms segregated to the dislocations is proportional to the concentration of solute $\mathrm{C}$ in the matrix and the $2 / 3$ power of time. Harper $\left.{ }^{2}\right)$ considered the saturation effect of segregation and obtained the extended model shown in Eq. (3):

$$
W=\frac{n_{t}}{n_{0}}=1-\exp \left[-3 L\left(\frac{\pi}{2}\right)^{\frac{1}{3}}\left(\frac{A D t}{k T}\right)^{\frac{2}{3}}\right]
$$

where $n_{t}$ is the number of solute atoms segregated per unit length of dislocation at time $t, n_{0}$ is the number of solute atoms per unit volume of matrix, $L$ is the total length of dislocations per unit volume, $A$ is the interaction energy between a dislocation and a solute atom and $D$ is the diffusion coefficient of an interstitial solute. Equation (3) can be rewritten as the following Eq. (4):

$$
\ln (1-W)=-\left(\frac{t}{\tau}\right)^{\mathrm{n}}=-(k t)^{\mathrm{n}}
$$

where $\tau, k$ are constants depending on the temperature. The parameter $W$ is often equated with the fractional increase in YP during aging, $\Delta \sigma / \Delta \sigma_{\max }$, where $\Delta \sigma$ is the increase in YP for time $t$ and $\Delta \sigma_{\max }$ is the maximum increase in YP during the aging process. ${ }^{28)}$ Figure 9 shows the result of an analysis of the kinetics of 1 st hardening by Eq. (4). The exponential, $\mathrm{n}$, is from 0.65 to 0.70 for the 1 st hardening and is independent of grain size. This is close to the $2 / 3$ given for Cottrell locking.

Figure 10 shows the apparent activation energies of the 1 st and 2nd hardening estimated for several $\Delta Y P$ levels. The apparent activation energy of the 1st hardening is from 83 to $86 \mathrm{~kJ} / \mathrm{mol}$, which is independent of grain size and is close to the activation energy of the volume diffusion of $\mathrm{C}$ atoms in $\alpha-\mathrm{Fe}^{29)}$ shown in Table 3. Thus, the dominant mechanism for the 1st hardening would be dislocation pinning by solute $\mathrm{C}$ atoms.

The apparent activation energies change discontinuously from 83 to $86 \mathrm{~kJ} / \mathrm{mol}$ to around $135 \mathrm{~kJ} / \mathrm{mol}$ over $100^{\circ} \mathrm{C}$. This suggests that the mechanism of 2 nd hardening is different from that of 1 st hardening. Similar values ${ }^{30-32)}$ and the 
temperature dependensy ${ }^{32)}$ were mentioned in the previous reports, in which the phenomenon in high temperature was understood as clustering or precipitates, because the activation energy is large and it follows the formation of the Cottrell atmosphere. ${ }^{23,25)}$

The apparent activation energy of $135 \mathrm{~kJ} / \mathrm{mol}$ is also close to that of pipe diffusion and grain-boundary diffusion of $\mathrm{Fe}$ atoms $^{33,34)}$ and precipitation of $\eta$-carbide. ${ }^{36)}$ The activation energies of grain-boundary and pipe diffusion of $\mathrm{Mn}$ and $\mathrm{P}$ in $\alpha$-Fe would be close to that of Fe atoms, because those of volume diffusion in $\alpha$-Fe are close to that of $\mathrm{Fe}$ atoms. ${ }^{37,38)}$ They are the candidates of the essential rate-controlling factor of 2 nd hardening.

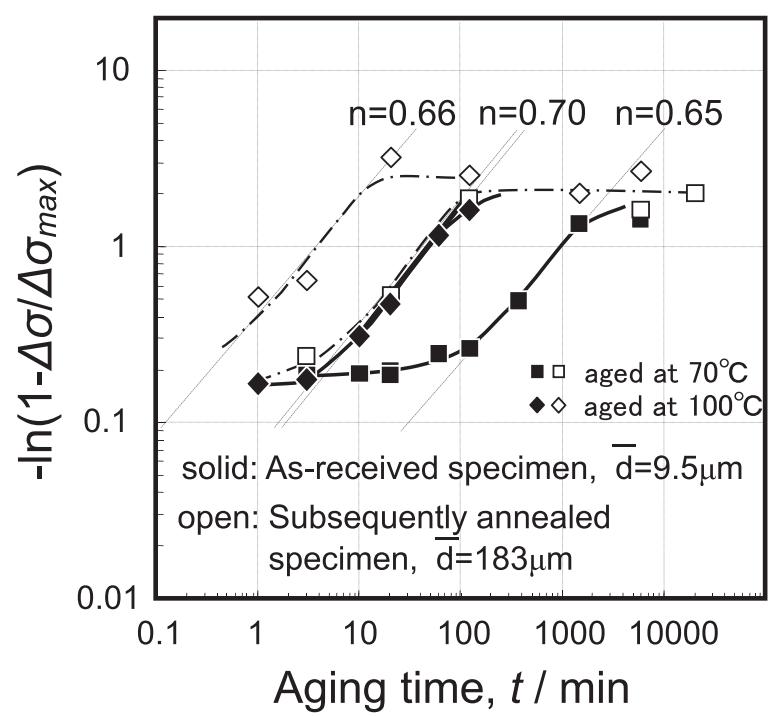

Fig. 9. Hardening kinetics of $2 \%$ pre-strained specimens with different grain sizes during 1st hardening stage analyzed by Harper model. ${ }^{2)}$

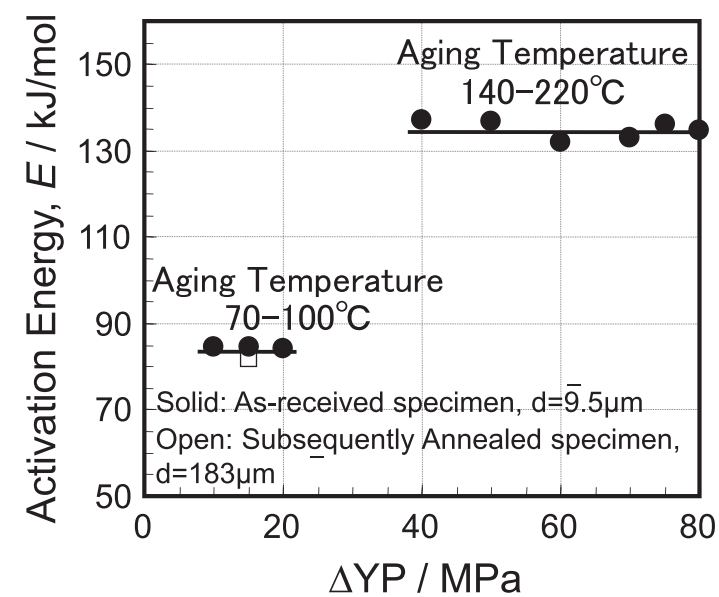

Fig. 10. Apparent activation energies estimated for several $\Delta \mathrm{YP}$ levels.
Previously been predicted, however, segregation of solute $\mathrm{C}$ to grain boundary may not be a predominant hardening factor, because the obtained apparent activation energy is approximately 1.5 times larger than that of volume diffusion of $\mathrm{C}$ atoms which is assumed to be rate-controlling in the grain-boundary segregation. Effect of the grain-boundary segregation during aging is discussed later in more detail as an additional enhancing factor of the age-hardening.

\subsection{Microstructural Changes during Aging}

Figure 11 shows a TEM micrograph of the fine-grained specimen aged at $170^{\circ} \mathrm{C}$ for 7 days. Fine precipitates are not observed either in the vicinity of the grain boundaries or within the grains, even under the peak hardening condition. Figure 12 shows the atomic distribution of the chief elements obtained by 3DAP analysis in the specimen aged at $170^{\circ} \mathrm{C}$ for 20 days. Segregation of solute C, Mn and P in the grain boundary is clearly observed. However, fine precipitates are not observed around the grain boundary. Figure 13 shows a TEM micrograph of the specimen aged at $170^{\circ} \mathrm{C}$ for 180 days. Similarly, fine precipitates are not observed even in the overaged region. This indicates that the 2 nd hardening which significantly appeared in the fine-grained steel is not due to the previously-predicted precipitation hardening. The softening behaviour is also not due to the coarsening of precipitates.

On the other hand, some changes in the dislocation structures are observed during aging. Apparently, two types of dislocations are developed, as shown in Fig. 13. One type of dislocation, which is adjacent to the grain boundary, is linear and is aligned vertical to the grain boundary; the other type

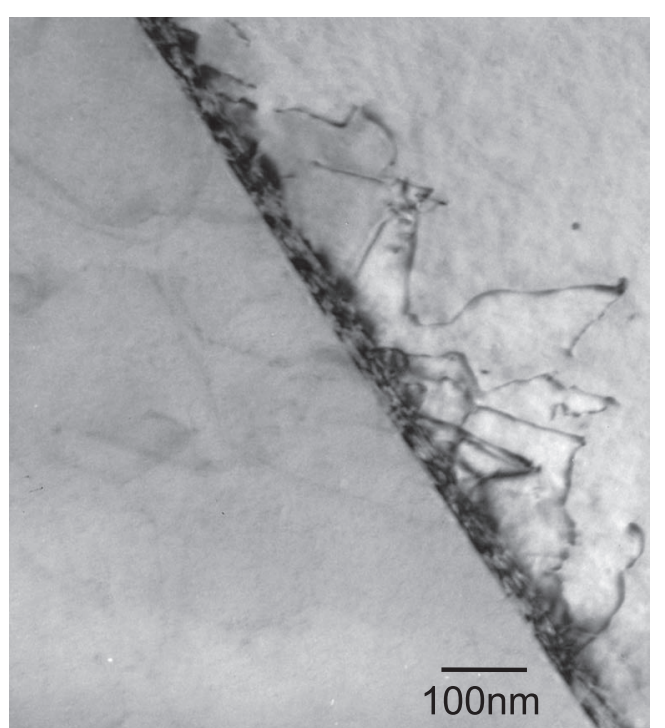

Fig. 11. TEM micrograph of as-received specimen aged at $170^{\circ} \mathrm{C}$ for 7 days.

Table 3. Activation energies of various mechanisms reported in previous studies.

$(\mathrm{kJ} / \mathrm{mol})$

\begin{tabular}{|c|c|c|c|c|c|c|}
\hline \multirow{2}{*}{$\begin{array}{l}\text { Volume diffusion } \\
\text { of } \mathrm{C}^{29)} \text { in } \alpha \text {-iron }\end{array}$} & \multicolumn{3}{|c|}{ Self diffusion in $\alpha$-iron } & \multirow{2}{*}{$\begin{array}{l}\text { Precipitation } \\
\text { of } \varepsilon \text { carbide }^{35)}\end{array}$} & \multirow{2}{*}{$\begin{array}{l}\text { Precipitation } \\
\text { of } \eta \text { carbide }^{36)}\end{array}$} & \multirow{2}{*}{$\begin{array}{c}\text { Precipitation } \\
\text { of cementite }^{36)}\end{array}$} \\
\hline & Pipe diffusion ${ }^{33)}$ & Volume diffusion $^{34)}$ & G.B. diffusion & & & \\
\hline $75-84$ & 134 & 241 & $241 \times(0.5-0.7)$ & 71 & $124 *$ & $176^{*}$ \\
\hline
\end{tabular}

*in martensitic steel 

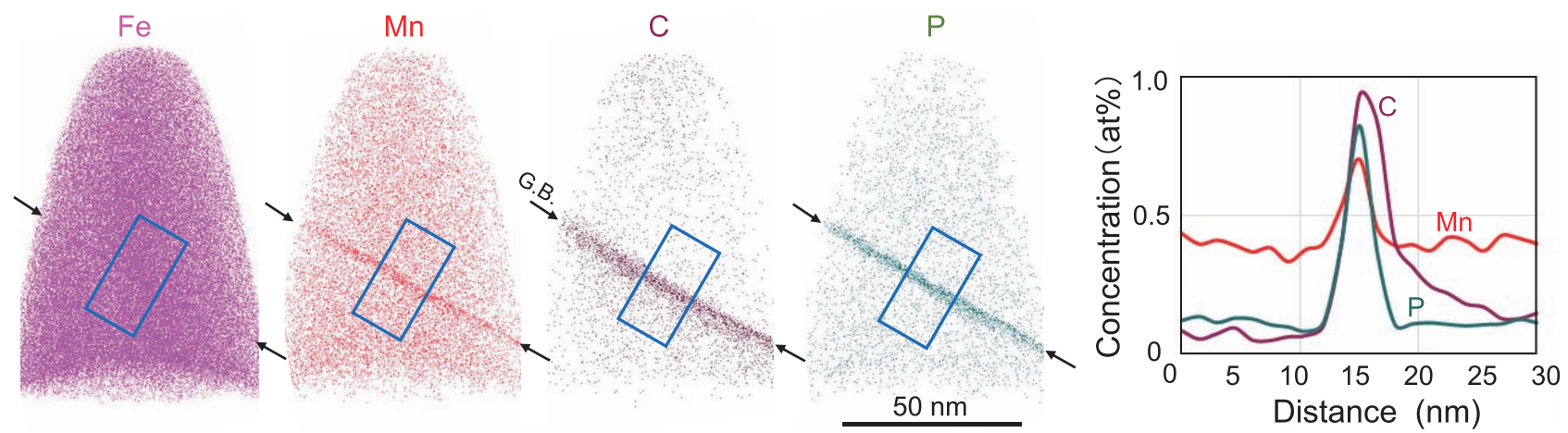

Fig. 12. Element mapping and concentration profile around grain boundary for several elements obtained by 3DAP in the as-received specimen aged at $170^{\circ} \mathrm{C}$ for 20 days.

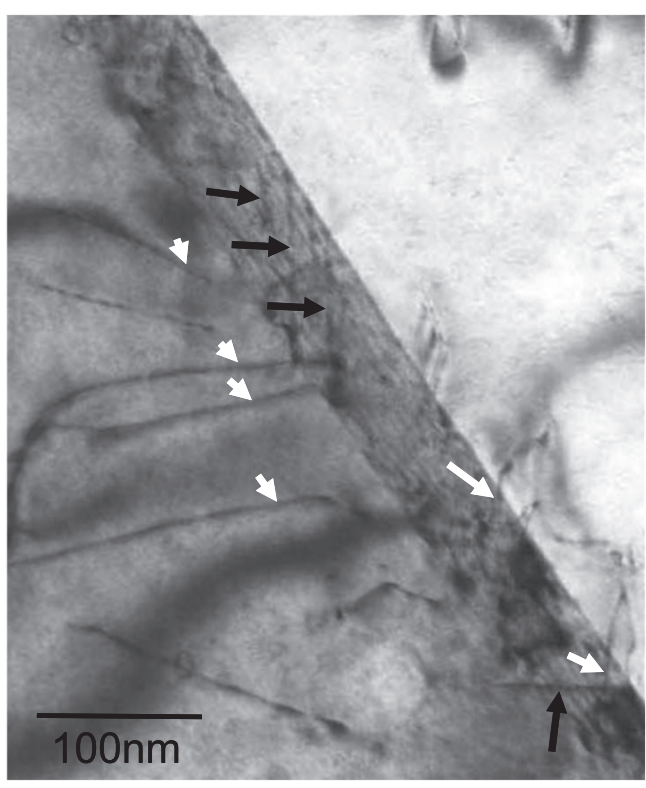

Fig. 13. TEM micrograph of as-received specimen aged at $170^{\circ} \mathrm{C}$ for 180 days. The black arrows show grain-boundary dislocations and the white arrows show dislocations arranged vertically to the grain boundary.

is a cluster of grain-boundary dislocations. These features are hardly observed in the specimen during the 1st hardening stage, but are clearly observed in the specimen aged at $400^{\circ} \mathrm{C}$. This indicates that $\mathrm{Fe}$ atoms can diffuse locally, in both the grain boundary and the dislocation core, with a long aging duration at over $100^{\circ} \mathrm{C}$.

\subsection{Effect of Diffusion of Elements around Grain Boundary}

Various mechanisms of the 2nd hardening are conceivable if the diffusion of elements around the grain boundary is considered. Previously predicted mechanism is the segregation of interstitial atoms into the grain boundaries. ${ }^{13)}$ The others would be segregation of substitutional atoms such as $\mathrm{P}, \mathrm{Mn}$ and $\mathrm{Nb}$ into the grain boundary, and changes in micro-residual stress ${ }^{14)}$ by dislocation movement, change in the dislocation structure and rearrangement and ordering of $\mathrm{Fe}$ or other atoms in the grain boundaries. Here, the effect of grain-boundary segregation of solute $\mathrm{C}$ was estimated first, after which the other possibilities were discussed.

McLean $^{39)}$ established a model expressing the velocity of grain-boundary segregation assuming a linear flow of solutes to the grain boundary as in Eq. (5):

$$
2 \sqrt{\left(D t_{0.5}\right)} /\left\{\left(C_{g b \infty} / C_{1}\right) \delta\right\}=3 / 4
$$

where $D$ is the diffusion coefficient of solutes, $t_{0.5}$ is the half-completion time, $C_{g b \infty}$ is the equilibrium concentration of solutes in the grain boundary, $C_{1}$ is the concentration of solutes in the matrix and $\delta$ is the thickness of the grain boundary.

The half-completion time, $t_{0.5}$, at $170^{\circ} \mathrm{C}$ is shown in Fig. 14. $C_{g b \infty}$ and $\delta$ are assumed to be 30 at $\%$ and 3 atomic diameters, respectively, and the amount of solute $\mathrm{C}$ within grains is varied to $1,3,10$ and $50 \mathrm{wt} . \mathrm{ppm}$. If the amount of solute $\mathrm{C}$ is 1 wt.ppm, $t_{0.5}$ is on the order of $10^{4} \mathrm{~min}$, which is close to the experimental result. Since the solubility of $\mathrm{C}$ in iron ${ }^{40)}$ is less than $1 \mathrm{ppm}$ at $170^{\circ} \mathrm{C}$, if more than $1 \mathrm{ppm}$ of solute $\mathrm{C}$ within a grain is assumed to diffuse to the grain boundary, the result based on the mass balance is an increase of more than $1 \mathrm{at} \%$ of solute $\mathrm{C}$ in the grain boundary, when the ferrite grain size is set to $9.5 \mu \mathrm{m}$ and width of the grain boundary is set to 3 atomic layers.

The influence of segregated solute $\mathrm{C}$ was analysed experimentally. Figure $\mathbf{1 5}$ shows a SEM micrograph of the fractured surface of an as-received specimen. Both the intergranular and cleavage fractured surfaces were analysed by AES. Since about 3 at $\%$ of $C$ was detected even at the cleavage fractured surface, this was subtracted as contamination.

Figure 16 shows the change in the concentrations of $\mathrm{C}$ and $\mathrm{P}$ at the intergranular fractured surface of aged specimens. Segregation of $\mathrm{C}$ seems to occur slightly during aging. The increment of the amount of $\mathrm{C}$ during aging is approximately $0.2-0.3 \mathrm{at} \%$, and the increment of $k_{y}$ is estimated as roughly $40-50 \mathrm{MPa} \mu \mathrm{m}^{1 / 2}$ from the experimental data. ${ }^{17)}$ This accounts for only $1 / 5$ of the total increment of $k_{y}$. One reason for this would be that the amount of initial solute $\mathrm{C}$ is already large in the grain boundary, because the steel sheet is gas-cooled after annealing and solute $\mathrm{C}$ is segregated during cooling. ${ }^{41)}$ This indicates that the segregation of solute $\mathrm{C}$ during aging contributes to age-hardening to some extent as an additional enhancing factor, but it is not a predominant rate-controlling factor.

Tanigawa $^{32)}$ reported that the cause of large activation energy above $100^{\circ} \mathrm{C}$ is not the addition of $\mathrm{Mn}, \mathrm{P}$ and the existence of $\mathrm{NbC}$, because large activation energy is also obtained in Al-killed steel. This indicates that segregation of substitutional elements such as $\mathrm{Mn}, \mathrm{P}$ and $\mathrm{Nb}$ may also have enhancing effects on age-hardening, but cannot be the 
dominant rate-controlling factor.

If segregation of elements during aging is slight, the recovery of the deformed grain boundary might be a candidate for the essential rate-controlling factor. As shown in Figs. 10 and 13, the apparent activation energy for the 2nd hardening is close to that of grain-boundary diffusion of Fe atoms, and the structure of the grain boundary seems to change gradually with increasing temperature. If local diffusion of $\mathrm{Fe}$ atoms takes place in the grain boundary, the

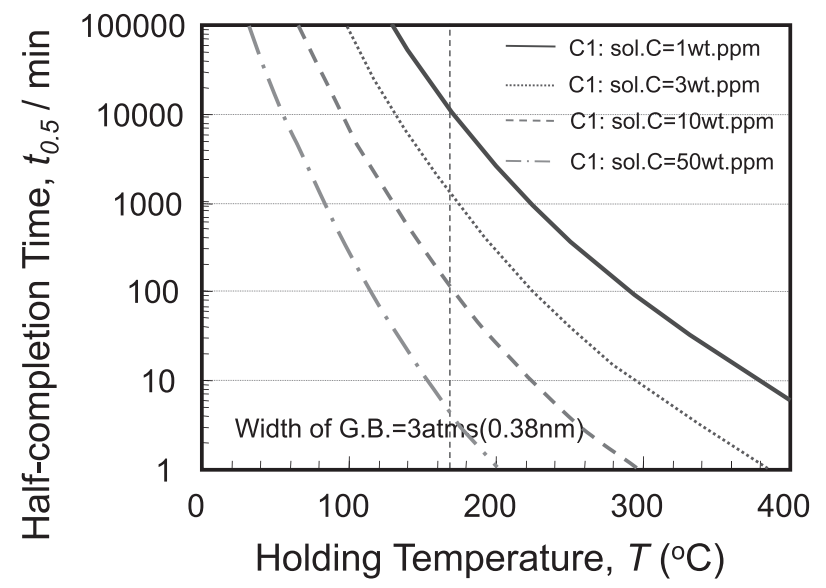

Fig. 14. Estimated half-completion time of grain-boundary segregation of $\mathrm{C}$ at $170^{\circ} \mathrm{C}$.

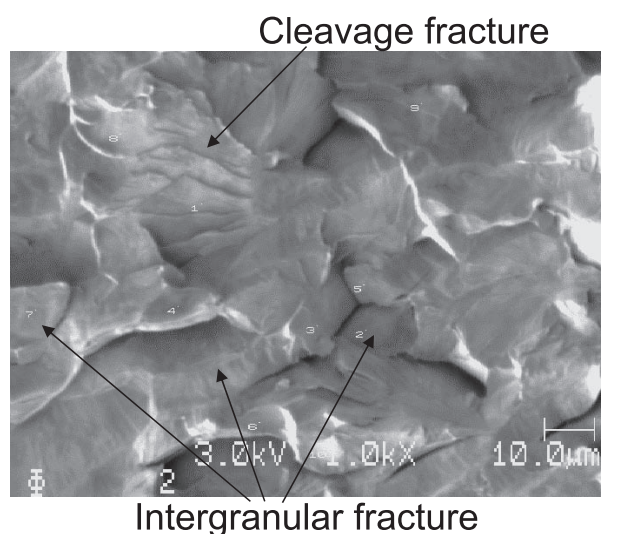

Fig. 15. SEM micrograph of fracture surface of as-received specimen fractured in vacuum chamber for AES analysis. structure of the grain boundary would become more stable during aging. Since the segregated solute $C$ in the grain boundary cause a quite large increase in $k_{y}$ in the annealed state rather than in the deformed state, such a grain boundary recovery process would cause the increase in $k_{y}$ in steel in which solute $\mathrm{C}$ is segregated before and during aging. These combined effects of embedded solute $\mathrm{C}$ and diffusion of $\mathrm{Fe}$ atoms in the grain boundary might be essential characteristics of the strain aging that appears over $100^{\circ} \mathrm{C}$. This is a new proposal, and will be discussed in detail in the subsequent report.

\subsection{Strain-aging Behaviour in Fine-grained Steel Con- taining Small Amount of Solute C}

Although the detailed microscopic mechanisms are still unclear, the general strain-aging behaviour of polycrystalline ferritic steel can be illustrated as shown in Fig. 17. The 1 st hardening would be due to dislocation pinning by solute $\mathrm{C}$, i.e., suppression of primary slip, and the 2 nd hardening would be due to grain boundary hardening, i.e., suppression of secondary slip.

The 1st hardening contributes to strain aging through an increase in $\sigma_{o}$ in Eq. (1). The hardening effect by dislocation pinning by solute $\mathrm{C}$ is around $30 \mathrm{MPa}$ at full aging. Since the segregation velocity is proportional to the concentration

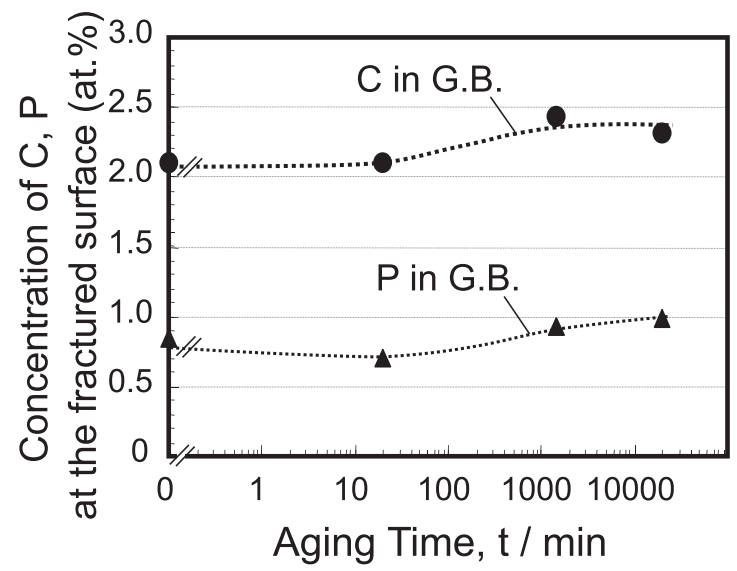

Fig. 16. Change in amounts of $\mathrm{C}$ and $\mathrm{P}$ at intergranular fractured surface of specimens aged at $170^{\circ} \mathrm{C}$.

\section{$1^{\text {st }}$ Hardening stage}

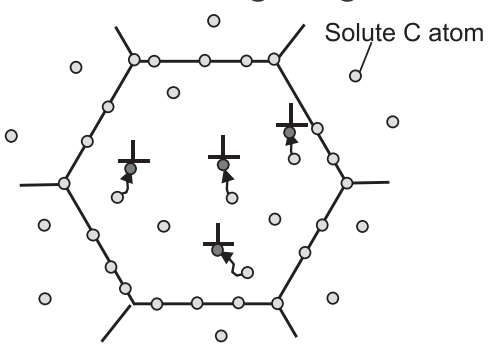

Dislocation pinning by solute $\mathrm{C}$

=>Suppression of Primary Slip

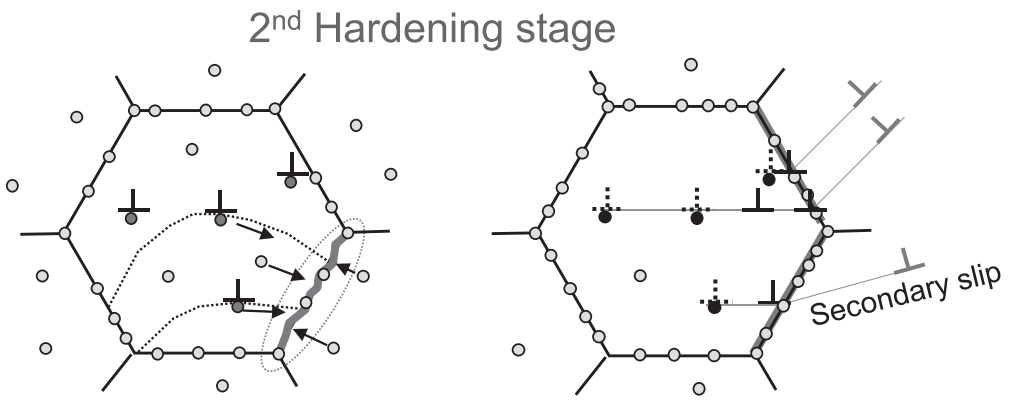

Grain-boundary hardening or hardening around it

$>$ Segregation of interstitial atoms to G.B., such as C,N13)

$>$ Segregation of substitutional atoms to G.B., such as P,Nb etc.

$>$ Grain-boundary diffusion or pipe diffusion of $\mathrm{Fe}$ atoms.

$$
=>\text { Suppression of Secondary Slip }
$$

Fig. 17. Presumable mechanisms and their illustrations for 1st and 2nd hardenings in the steel with fine grain and containing small amount of solute $\mathrm{C}$. 
of solute $\mathrm{C}^{1)}$ and the pinning sites are fully occupied by the quite small amount of solute $\mathrm{C}$, the amount of solute $\mathrm{C}$ affects the hardening rate, but it hardly affects the maximum hardening value.

The 2nd hardening contributes to strain aging through an increase in $k_{y}$, if the amount of solute $\mathrm{C}$ within the grain is small and precipitation is slight. In the 2 nd hardening, the large apparent activation energy of $135 \mathrm{~kJ} / \mathrm{mol}$ is necessary; the 2nd hardening appears significantly at elevated temperature. Such a hardening effect is enhanced in finegrained steel from Eq. (1). These points are consistent with the previously-reported features of bake-hardenable steel. ${ }^{3,13)}$ Addition of micro-alloying element such as $\mathrm{Nb}$ would contribute to hardening through grain refinement. Many researchers ${ }^{16,32,42)}$ have pointed out the limitation of the applicability of Hundy's equation, ${ }^{43)}$ which is based on the Cottrell's model. ${ }^{1)}$ One of the reasons for this might be the onset of the increase in $k_{y}$ because the deviation occurs at over $100^{\circ} \mathrm{C}^{16,32,42)}$ accompanying the large apparent activation energy of $140 \mathrm{~kJ} / \mathrm{mol}^{32}$ )

If the amount of solute $\mathrm{C}$ within the grain becomes larger, the amount of segregated solute $\mathrm{C}$ in the grain boundary before and during aging would also become larger, and if it exceeds the solubility in ferrite, precipitation would occur. The former would enhance the age-hardening through an increase in $k_{y}$ and the latter, through an increase in $\sigma_{o}$.

\section{Conclusions}

The strain-aging mechanisms of polycrystalline ferritic steel were investigated using Nb-bearing ULC steel sheets with ferrite grain sizes of $9.5 \mu \mathrm{m}$ and $183 \mu \mathrm{m}$, which contained a quite small amount of solute carbon. The major conclusions are as follows:

(1) The fine-grained specimens exhibited two distinct hardening stages, whereas large-grained specimens showed only a single hardening stage. The increase in YP in the 1st hardening stage is around $30 \mathrm{MPa}$, and the apparent activation energy of this stage is estimated to be from 83 to $86 \mathrm{~kJ} /$ mol. The increase in YP in the 2nd hardening stage reaches $90 \mathrm{MPa}$, and the apparent activation energy is $135 \mathrm{~kJ} / \mathrm{mol}$.

(2) The 1st hardening stage progresses proportionally to approximately the $2 / 3$ power of time, and its apparent activation energy is close to that of $\mathrm{C}$ diffusion in bcc Fe. Therefore, the predominant mechanism of hardening in this stage is assumed to be dislocation pinning by solute $\mathrm{C}$ atoms.

(3) The 2nd hardening stage progresses accompanying a large increase in the Hall-Petch coefficient, $k_{y}$. During this process, fine precipitates do not exist. The 2nd hardening is presumed to be associated with grain-boundary hardening. Local diffusion of $\mathrm{Fe}$ atoms around grain boundaries where solute $\mathrm{C}$ is embedded is proposed as an essential mechanism of the 2nd hardening. The grain-boundary segregation of solute $\mathrm{C}$ during aging could promote the primary mechanism.

\section{Acknowledgement}

Discussions in the ISIJ forum on "Fundamentals of the behaviour of light elements in steels and their effects on mechanical properties" and research group on "Light elements in steels and their roles in microstructure and properties" are gratefully acknowledged.

\section{REFERENCES}

1) A. H. Cottrell and B. A. Bilby: Proc. Phys. Soc. A, 62 (1949), 49.

2) S. Harper: Phys. Rev., 83 (1951), 709.

3) S. Hanai, N. Takemoto, Y. Tokunaga and Y. Mizuyama: Trans. Iron Steel Inst. Jpn., 24 (1984), 17.

4) A. K. De, S. Vandeputte and B. C. De Cooman: J. Mater. Eng. Perform., 10 (2001), 567.

5) D. V. Wilson and B. Russel: Acta Metall., 8 (1960), 468.

6) A. K. De, S. Vandeputte and B. C. De Cooman: Scr. Mater., 44 (2001), 695.

7) N. Maruyama and M. Takahashi: Tetsu-to-Hagané, 93 (2007), 32.

8) A. S. Keh and W. C. Leslie: Mater. Sci. Res., 1 (1963), 208.

9) D. V. Wilson and B. R. Russell: Acta Metall., 8 (1960), 36.

10) K. Fujii, D. Akama, N. Nakada, T. Tsuchiyama and S. Takaki: CAMP-ISIJ, 25 (2012), 1135, CD-ROM.

11) M. Kinoshita and A. Nishimoto: CAMP-ISIJ, 3 (1990), 1780

12) A. V. Snick, K. Lips, S. Vandeputte, B. C. De Cooman and J. Dilewijns: Modern LC and ULC Sheet Steels for Cold Forming, Vol. 2, ed. by W. Bleck, Verlag Mainz, Aachen, (1998), 413.

13) D. V. Wilson: Met. Sci., 1 (1967), 40.

14) H. P. Tardif and C. S. Ball: J. Iron Steel Inst., 182 (1956), 9.

15) B. B. Hundy: Metallurgica, 53 (1956), 203.

16) J. D. Baird: Iron Steel, 36 (1963), 186

17) K. Takeda, N. Nakada, T. Tsuchiyama and S. Takaki: ISIJ Int., 48 (2008), 1122.

18) J. Takahashi, K. Kawakami, K. Ushioda, S. Takaki, N. Nakada and T. Tsuchiyama: Proc. 3rd int. Symp. on Steel Science, ISSS2012, ISIJ, Tokyo, (2012), 69.

19) S. Takaki, D. Akama, N. Nakada and T. Tsuchiyama: Mater. Trans., 55 (2014), 28.

20) G. K. Williamson and R. E. Smallman: Acta Crystallogr., 7 (1954), 574.

21) K. Nakashima, Y. Futamura, H. Hidaka, T. Tsuchiyama and S. Takaki: CAMP-ISIJ, 17 (2004), 396.

22) K. Nakaoka, K. Araki, Y. Takada and J. Nose: NKK Tech. Rep., 75 (1977), 253.

23) R. Armstrong, I. Codd, R. M. Douthwaite and N. J. Petch: Philos. Mag., 7 (1962), 45.

$24)$ E. O. Hall: Proc. Phys. Soc. B, 64 (1951), 747

$25)$ N. J. Petch: J. Iron Steel Inst., 174 (1953), 25.

26) Y. Ono, K. Okuda, Y. Funakawa and K. Seto: Mater. Sci. Forum, 706-709 (2012), 2222.

27) J. F. Butler: Acta Metall., 10 (1962), 258.

28) W. C. Leslie: The Phisical Metallurgy of Steels, McGraw-Hill, New York, (1982), 88.

29) C. Wert: Phys. Rev., 79 (1950), 601.

30) M. S. Rashid: Metall. Trans. A, 7A (1976), 497.

31) A. K. Panda, R. I. Ganguly and S. Misla: Steel Res., 63 (1992), No. 3, 131 .

32) K. Tanigawa, Y. Hosoya and T. Koike: NKK Tech. Rep., 145 (1994), 25 .

33) M. Cohen: Trans. Jpn. Inst. Met., 11 (1970), 145.

34) D. W. James and G. M. Leak: Philos. Mag., 14 (1966), 701.

35) R. H. Doremus: Trans. Metall. Soc. AIME, 218 (1960), 596.

36) T. Waterschoot, K. Verbeken and B. C. De Cooman: ISIJ Int., 46 (2006), 138

37) K. Nohara and K. Hirano: Proc. Int. Conf. on Science and Technology of Iron and Steels, ISIJ, Tokyo, (1971), 1267.

38) T. Matsuyama, T. Hosokawa and H. Suto: Trans. JIM, 24 (1983), No. $8,589$.

39) D. McLean: Grain Boundaries in Metals, Clarendon Press, Oxford, (1957).

40) D. McLean: Mechanical Properties of Metals, Wiley, New York, (1962), 208

41) V. A. Phillips: Acta Metall., 11 (1963), 1139.

42) E. Shuto, T. Shibai, K. Arase and S. Fujita: Tetsu-to-Hagané, 48 (1962), 1375.

43) B. B. Hundy: J. Iron Steel Inst., 178 (1954), 34. 